\title{
Modelling the selective effects of fishing on reproductive potential and population structure of squid
}

\author{
E. J. Murphy, P. G. Rodhouse, and C. P. Nolan
}

Murphy, E. J., Rodhouse, P. G., and Nolan, C. P. 1994. Modelling the selective effects of fishing on reproductive potential and population structure of squid. - ICES J. mar. Sci., 51: 299-313.

Artificial selection processes associated with harvesting may operate over relatively short time scales in short-lived semelparous species. The ommastrephid squid Illex argentimus on the Patagonian Shelf is the target of a major fishery. Recent work has provided new information on the biological characteristics of squid in this fishery. That information has been utilized in the development of a model of the cohort dynamics and some of the within-season selective effects considered. The model results are consistent with earlier data from the shelf fisheries, supporting suggestions that the males mature and migrate earlier towards the spawning grounds than the females. Earlier maturation results in a smaller mean size in the spawning stock, while later maturation results in greater exposure to the fishery and a reduced number of individuals surviving to spawn. Under the current fishing regime greater egg production and a larger spermatophoric complex mass for the whole cohort is achieved by relatively late maturation. In general, however, the earlier maturation occurs, the earlier is the peak in total egg production. The within-season pattern of effort expenditure in the fishery can affect not only yield from the fishery but also the reproductive potential of the spawning stock. The management policy adopted for this fishery is likely to be conservative in terms of maintenance of a spawning stock; however, the potential for selective effects is large and this may affect both yield and reproductive potential. The results are discussed in relation to short- and long-term effects in the fishery and the implications for future research requirements.

Key words: model, squid, population dynamics, reproductive potential, selection.

Received 29 June 1993; accepted 4 February 1994.

E. J. Murphy, and P. G. Rodhouse: British Antarctic Survey, Natural Environment Research Council, High Cross, Madingley Road, Cambridge CB3 OET, England, C. P. Nolan: FIG Fisheries Department, Port Stanley, Falkland Islands, South Atlantic.

\section{Introduction}

Fisheries for short-lived semelparous squid species impact on the structure of exploited populations in the short term and might be expected, through the influence of selective effects, to influence life-history traits in the longer term. At high rates of exploitation the selective effects can alter the age, size, and breeding structure of populations, and in the longer term these artificial selection processes may drive evolution of the exploited stocks in unintended directions, which may have damaging consequences for yield (Law and Grey, 1989). Obtaining data to address such questions is likely to remain extremely difficult. Modelling provides a tool which can be used to investigate some of the potential selective effects occurring in a fishery. One of the key aspects of the life history of some short-lived semelparous squid species that provides potential for selection to occur is the seasonal migration.
The definition of a unit stock is complicated by seasonal migration effects, and this is particularly the case for populations in which the immigration and emigration phases occur during the exploited phase. One of the consequences of such migration is that the stock size estimated by sampling the population on the ground may be a poor index of the potential spawning stock size. The size and composition of the spawning stock may be crucial to the long-term survival of the population. This is likely to be particularly important in annual species where the spawning stock characteristics are determined by only a single fishing season. In such situations the potential affect on the reproductive success is likely to be greater, and this may have long-term implications for sustainability.

The fishery for the Ommastrephid squid Illex argentinus is a useful system for investigating some of these questions. The largest proportion of fishing effort on Illex argentinus on the Patagonian Shelf is attributed to

(C) 1994 International Council for the Exploration of the Sea 


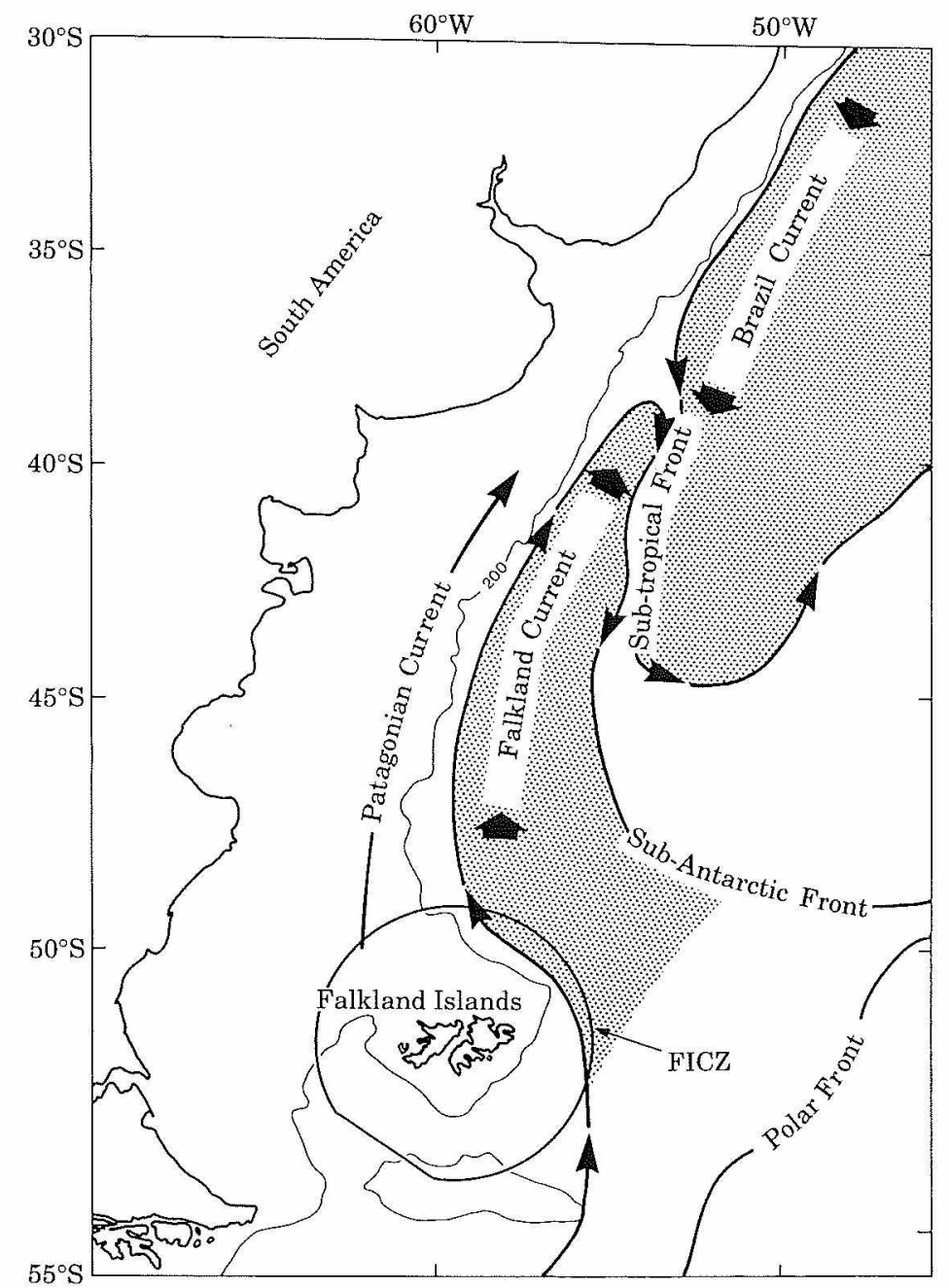

Figure 1. Map of the Patagonian Shelf region showing the Falkland Island Conservation Zone (FICZ) around the islands, the major water types (stippled), the major currents (black arrows), and general circulation (small black arrows).

jigging vessels in the waters around the Falkland Islands and the offshore Patagonian Shelf and Slope area between $42^{\circ}$ and $48^{\circ} \mathrm{S}$ (Csirke, 1987). Since 1987 the Falkland Islands Fishery has been managed within the context of the Falklands Interim Conservation and Management Zone (FICZ), which covers an area of 150 -mile radius from a point in the centre of the Islands, excluding an area in the south-west (Fig. 1). More recently this has been extended to include an outer conservation zone. Vessels are licensed to fish within the FICZ between March and May/June, but fishing on the same stock takes place outside the zone in international waters and within the Argentinean EEZ. Within the FICZ, management of the stock is based on a target proportional escapement policy effected by effort limitation. The management target for proportional escapement in the FICZ is 40\% (Beddington et al., 1990), but realized escapement may be higher. In considering the dynamics of this stock natural and fishing mortality rates have been included (Beddington et al., 1990; Rosenberg et al., 1990). Only recently has information become available on maturation and other biological aspects (Rodhouse and Hatfield, 1990; Rodhouse et al., 1990), which can be used to develop further biological models of the population dynamics.

On the southern part of the Patagonian Shelf the Illex argentinus completes its life cycle in approximately 1 year. At age 1 year the approximate mantle length is $295 \mathrm{~mm}$ for males and $347 \mathrm{~mm}$ for females, but there is variability in growth rate and maximum size which are related, at least in part, to the hatching date (Arkhipkin, 1990; Rodhouse and Hatfield, 1990). Sexual maturation occurs simultaneously with growth during the latter half of the squid's life and there is variability within each 
Table 1. Seasonal pattern of fishing effort (number of hours fished by the licensed fleet) during three seasons, 1987-1989. The standard proportional effort is the mean over the three seasons of the effort expended each month, expressed as a proportion of the total season effort. This is taken as the standard fishing regime.

\begin{tabular}{lrrrr}
\hline & \multicolumn{3}{c}{ Year } & \\
\cline { 2 - 4 } Month & \multicolumn{1}{c}{1987} & \multicolumn{1}{c}{1988} & \multicolumn{1}{c}{1989} & Standard proportional effort \\
\hline January & 0.00 & 166.27 & 0.00 & 0.00 \\
February & 2135.40 & 1605.27 & 237.22 & 0.01 \\
March & 19603.60 & 34141.77 & 26644.37 & 0.20 \\
April & 41783.07 & 39174.97 & 49892.55 & 0.37 \\
May & 38646.68 & 38367.00 & 45407.18 & 0.34 \\
June & 2811.02 & 9231.57 & 10543.52 & 0.06 \\
July & 0.00 & 57.25 & 0.00 & 0.00 \\
\hline
\end{tabular}

year class in the rate of maturation and in size at full maturity (Rodhouse and Hatfield, 1990). Squid maturing early in the season do so at a smaller size than those maturing late (Rodhouse et al., 1990). At the end of the squid's 1-year life, mating and spawning is followed by death. There is no evidence that any Illex argentinus survive into a second year.

The squid migrate into the FICZ from the north and arrive between January and March. The catch rate peaks in March and April and most Illex are caught to the north of the Islands. As the squid grow and mature they migrate out of the zone towards the west and then probably migrate northwards to an unknown spawning location. By June catch rates have fallen to zero as the last squid leave the zone. Males arrive in larger numbers at the beginning of the fishing season and depart sooner than females so that the male-to-female ratio in the catch declines between March and June (Rodhouse et al., 1990).

There have been a range of models developed for Illex fisheries (Sissenwine and Tibbets, 1976; Hurley and Mohn, 1979) and some attempts have been made to include aspects of migration. Caddy (1979) has generated a three-phase model for application to the Illex illecebrosus fishery in the north-west Atlantic. That model was used mainly to investigate the fishery itself rather than the effects of the fishery on the biology of the exploited species.

In this paper we model the effects on reproductive potential of fishing on an annual species which migrates onto the fishing grounds to feed, grow and mature, and then migrates out of the fishery upon attaining maturity. There is therefore a size-selective element in this fishery which will favour those individuals which mature early [by implication at a smaller size (Rodhouse et al., 1990)] and migrate out of the fishery earlier than late maturers, thus reducing the proportion of their lifetime exposed to the fishing gear and the probability of their capture. This work is considered to be the first stage in the develop- ment of models considering the selective effects of exploitation of short-lived semelparous species.

\section{Modelling the dynamics of a cohort}

The key elements of the cohort dynamics of the Illex argentimus fishery can be summarized as follows. The fishery operates over a 5-month season from February, although in some years there have been catches in January and July (Table 1). The catch is sampled during the course of the season so the change in the length frequency distributions through the seasons can be monitored. Three processes reduce the number of the squid in the cohort on the fishing ground; natural mortalities (e.g. predation), fishing mortalities, and emigration from the ground associated with maturation. Growth and maturation occur simultaneously through the season.

The model described below was constructed in a discrete form in time and males and females were treated separately. For simplicity it was assumed that the whole population recruits at the start of the season. The model has been used to simulate the effects of changes in maturation rates on reproductive potential.

\section{Growth}

Over the period of the fishing season growth, in terms of mantle length, can be approximated by a linear relationship (Rodhouse and Hatfield, 1990). The relationships for males and females are given in Table 2 and these were applied in the model. The growth rates are, therefore, assumed to be constant for all animals throughout the season. The simulation of the cohort dynamics was based on a population composed of discrete size classes, as this was the form of the data available. To model the growth we calculate the number of increment classes (g) through which the whole cohort grows during a time interval $\delta \mathrm{t}$. This is given by: 
Table 2. Regression relationships used in model (Rodhouse and Hatfield, 1990). All mass estimates are in grams, mantle length is in millimetres, and time in days. ( $\mathrm{SC}=$ spermatophoric complex.)

\begin{tabular}{|c|c|c|}
\hline Linear relationship & Constant (A) & Slope (b) \\
\hline \multicolumn{3}{|c|}{ (Mantle length) $=\mathrm{A}+\mathrm{b}$ (time) } \\
\hline Males & 70.9 & 0.61 \\
\hline Females & 15.6 & 0.91 \\
\hline \multicolumn{3}{|c|}{$\ln$ (body mass) $=\mathrm{A}+\mathrm{b} \ln$ (mantle length) } \\
\hline Males & -14.3 & 3.68 \\
\hline Females & -13.0 & 3.40 \\
\hline \multicolumn{3}{|c|}{$\ln$ (ovary mass) $=\mathrm{A}+\mathrm{b} \ln$ (body mass) } \\
\hline Females & -3.72 & 1.23 \\
\hline \multicolumn{3}{|c|}{$\ln (\mathrm{SC} M)=\mathrm{A}+\mathrm{b} \ln ($ mantle length) } \\
\hline Males & -34.8 & 6.64 \\
\hline
\end{tabular}

$\mathrm{g}=\frac{\beta \delta \mathrm{t}}{\delta \mathrm{L}}$,

where $\beta$ is the growth rate $\left(\mathrm{mm} \mathrm{d}^{-1}\right), \delta$ is the time interval (days), and $\delta \mathrm{L}$ the size-class increment ( $\mathrm{mm}$ ). If $\mathrm{g}$ is an integer value then the distribution maps directly into the increment classes of the length scale. If $g$ is a real number then animals in any given size class $(k)$ grow into two consecutive size classes: $\mathrm{k}+\mathrm{j}$ and $(\mathrm{k}+\mathrm{j})+1$, where $\mathrm{j}$ is the integer part of $\mathrm{g}$. Within each size class the animals were assumed to be uniformly distributed. Then the remainder of $\mathrm{g}-\mathrm{j}$ gives the proportion of the animals entering the larger of the two size classes. The rest enter the smaller size class. So, of the $\mathrm{N}_{(\mathrm{k}, \mathrm{t})}$ individuals in class $k$ at time $t$ there will be $N_{(k+j, t+1)}=N_{(k, t)}$ $(1-(g-j))$ individuals in class $k+j$ at time $t+1$ and $\mathrm{N}_{(\mathrm{k}+\mathrm{j}+1,1+1)}=\mathrm{N}_{(\mathrm{k}, \mathrm{t})}(\mathrm{g}-\mathrm{j})$ individuals in class $\mathrm{k}+\mathrm{j}+1$. This process was applied to all size classes at each time step and the resultant frequencies summed in each size class to generate the new length frequency distribution at time $\mathrm{t}+1$.

\section{Natural mortality}

For this type of organism the value of the instantaneous rate of natural mortality $(\mathrm{M})$ is often considered to be high. Beddington et al. (1990) used a value of 2.9 (annual) (equivalent to 0.06 per week). In this semelparous species the concept of a constant natural mortality is unlikely to be appropriate. There is a catastrophic mortality after spawning so natural mortality may be relatively low during the period prior to this. Caddy (1990) considered a changing value of $M$ with age and suggested that it was reasonable to assume a relatively constant value for the last 6 months prior to spawning. To examine the effect of different values of $M$ two values were used in the simulations of the cohort dynamics: $\mathrm{M}=2.9$ and a low level of 0.5 .

\section{Maturity}

Key features of interest are the number and size of adults that mature and emigrate from the fishing grounds. It was assumed for modelling purposes that a function can be defined which describes the rate of the maturation of the cohort each month. This function was defined separately for each sex, but it was assumed to be independent of size. Five seasons of data (1987-1991) were available to investigate the proportion of the squid cohort mature during each month period (Fig. 2). It was assumed that the squid becoming mature each month leave the area of the fishery and successfully reach the spawning grounds. Thus, the proportion data are assumed to reflect the rate of maturation of the cohort. These data (Fig. 2) were approximated by a simple logistic function which allows the sensitivity of the model population dynamics to be investigated. The functional form is:

$P_{t}=\left[\frac{P_{\max }}{1+e^{-(t-k)}}\right]$,

where $P_{t}$ is the rate of maturation of the squid cohort at time $t, P_{\max }$ is the maximum rate of maturation of the cohort in a month, and $\mathrm{k}$ is the time at which $\mathrm{P}_{\max } / 2$ of the squid become mature. The instantaneous rate of maturation is then given by $\mathrm{Mat}_{\mathbf{t}}=-\ln \left(1-\mathrm{P}_{\mathbf{1}}\right)$.

Maximum likelihood methods (Payne et al., 1987) were used to fit the logistic function to the maturation data. With migration when maturity is reached the application of the above function implies that the rate of maturation increases with time. This is not unreasonable as the whole cohort becomes increasingly more mature with time. So, of the squid that are not yet fully mature, an increased proportion will become mature later in the season.

\section{Spawning}

Empirical relationships (Table 2) were used to calculate the total egg production each month on the basis of the size distribution of female squid maturing and migrating out of the fishery. For conversion of ovary mass into egg production a mean ratio of $2.5 \times 10^{5}$ eggs produced per $81 \mathrm{~g}$ of ovarian tissue was used (Rodhouse and Hatfield, 1990). No delay was introduced into the model for the migration to the spawning grounds. The total spermatophoric complex mass was also calculated to give an index of the male reproductive potential (Table 2).

\section{Fishing}

The seasonal pattern of effort distribution in the fishery between 1987 and 1989 was not uniform (Table 1), but showed a peak between March and May. As we are interested in the number of mature animals leaving the 

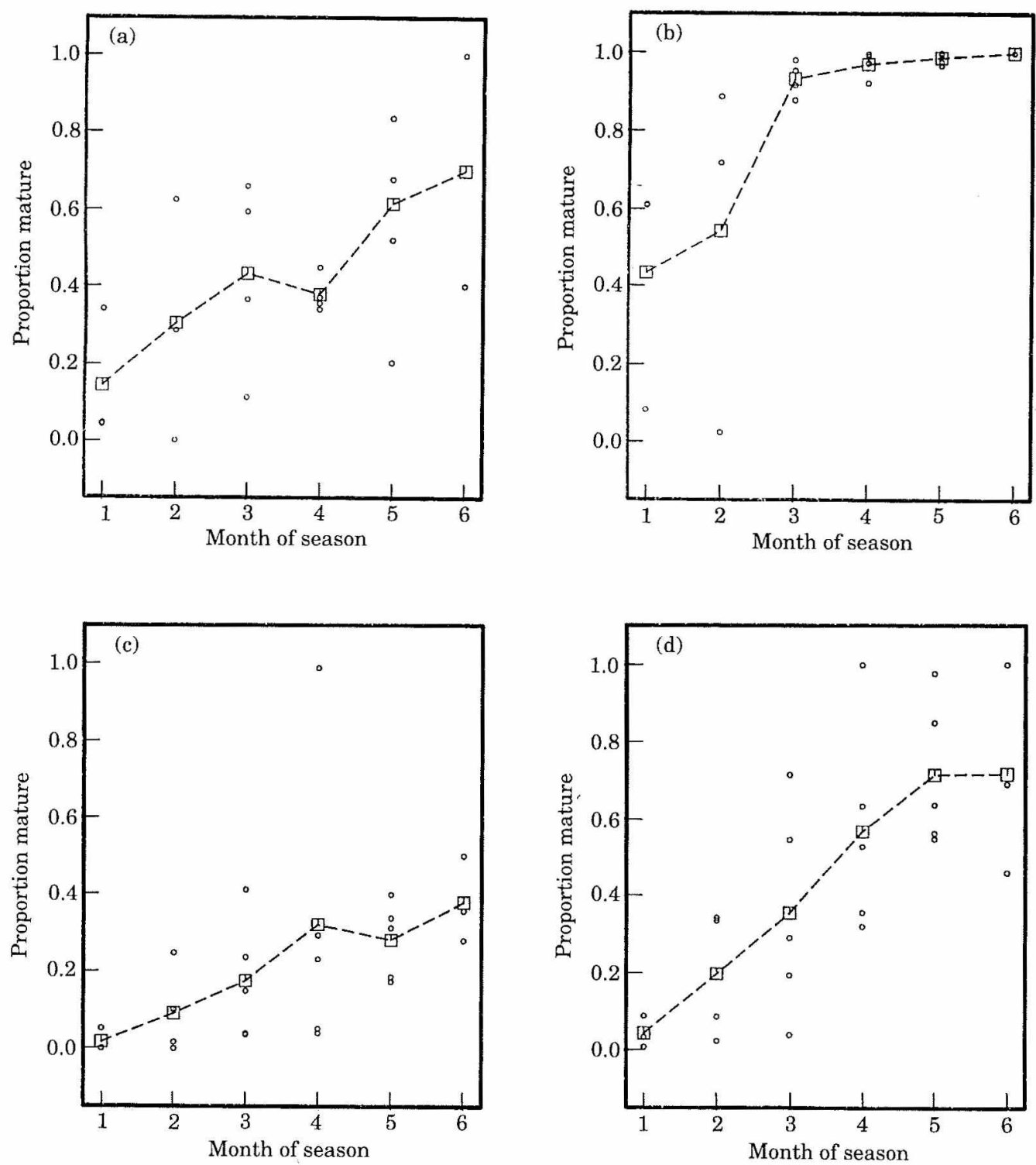

Figure 2. The seasonal change in the proportion of mature Illex (circles) in the catch for the period from 1987-1991. The mean for each month, starting from January, is shown by the broken line (squares). (a) Male stage V. (b) Male stages IV+V. (c) Female stage V. (d) Female stages IV +V.

fishery each month, assuming a constant rate of instantaneous fishing mortality (F) will not be very useful. Monthly estimates of $F_{i}$ ( $i$ is the month) are unavailable at present. However, the management strategy adopted for the fishery allows us to obtain an estimated vector for $F$ which will satisfy the escapement policy for the fishery.

For constant $\mathrm{F}$ the proportional escapement $(\mathrm{X})$ is given by:

$\mathrm{X}=\mathrm{e}^{-\mathrm{F}}$.
The instantaneous fishing mortality rate is related to the fishing effort $(\mathrm{E})$ by the relationship $\mathrm{F}=\mathrm{qE}$, where $\mathrm{q}$ is the catchability coefficient. For constant monthly values of $\mathrm{q}_{\mathrm{i}}$ (Rosenberg et al., 1990) over a season of $\mathrm{n}$ months (i), the escapement is given by:

$\mathrm{X}=\mathrm{e}^{-\left(\sum_{i=1}^{n} \mathrm{q}_{\mathrm{i}} \mathrm{E}_{\mathrm{i}}\right)}$

We do not know $q_{i}$ or the absolute values of $E_{i}$, but we do have estimates of the relative sizes of $E_{i}$ (Table 1). 
Thus, assuming all $\mathrm{q}_{\mathrm{i}}=1$ then the relative pattern of $E_{i}$ observed can be used to satisfy Equation (4). Such that:

$-\ln (\mathrm{X})=\sum_{i=1}^{n} \mathrm{E}_{\mathrm{i}}$

and

$\mathrm{F}_{\mathrm{i}}=-\ln (\mathrm{X})\left(\frac{\mathrm{E}_{\mathrm{i}}}{\sum_{i=1}^{n} \mathrm{E}_{\mathrm{i}}}\right)$.

Where $E_{i}$ is the observed effort and $F_{i}$ is the fishing mortality rate during month $\mathrm{i}$. The fishing impact was assumed to be independent of sex. The escapement was defined from the start of the fishing season (FICZ). The output from the model allows the proportional escapement to be examined. Changing the fishing impact and effort distribution allows the escapement to be changed.

Then the numbers remaining at a time $t+1$ is given by:

$N_{t+1}=N_{t} e^{-\left(F_{1}+M+M a t_{t}\right)}$,

where $N_{t}$ is the number of squid at time $t, N_{t+1}$ is the number of squid at time $t+1, M$ is the instantaneous natural mortality rate, $\mathrm{F}_{\mathrm{t}}$ is the instantaneous fishing mortrality rate, and $\mathrm{Mat}_{\mathrm{t}}$ is the instantaneous rate of maturation. All rates are based on a time interval of $t$ to $t+1$. It was assumed that the various rates were constant for the whole time interval. The numbers caught $\left(C_{t}\right)$ at time $t$ are given by:

$C_{t}=\frac{F_{t}}{F_{t}+M+M a t_{t}} N_{t}\left[1-e^{-\left(F_{t}+M+M a t_{t}\right)}\right]$

and the number maturing $\left(\mathrm{Nm}_{\mathrm{t}}\right)$ by:

$N m_{t}=\frac{M a t_{t}}{F_{t}+M+M a t_{t}} N_{t}\left[1-e^{-\left(F_{1}+M+M a t_{t}\right)}\right]$

The simulation was constructed such that growth occurred as a step function at the end of each time interval. Stock and catch biomasses were obtained using the body mass to mantle length relationships given in Table 2.

\section{Initial conditions for simulation}

To allow us to consider the dynamics over the whole season from January through to July the summed length-frequency distribution (10-mm size classes) for all squid sampled in January during all five seasons for which data were available (1987-1991) was taken as the initial recruitment distribution. The length-frequency distributions were scaled to begin the model runs with $7.5 \times 10^{4}$ squid of each sex. It was assumed that all squid recruit simultaneously onto the ground at the start of the season (1 January). As there is little exploitation prior to March this has little effect on the final results. The squid collected prior to March were obtained as a by-catch by vessels targeting other species, so there may be some effects caused by the type of gear employed. The data used do, however, provide a baseline against which the effects of variations in the recruitment distribution can be considered. The relative effort patterns during three fishing seasons (1987-1989) are shown in Table 1. The proportion of effort expended each month was calculated for each year. The mean over the 3 years gave the standard proportional effort pattern, which was used as the standard fishing regime in simulations.

\section{Results}

The classification of male and female Illex into five maturity stages is based on subjective criteria (Lipinski, 1979). At any time throughout the season in the FICZ there are relatively few Illex with stage $\mathrm{V}$ gonads. This fully-mature stage probably only occurs a short time before, or after, emigration from the fishing grounds. A better index of proportional maturation is likely to be given by the representation of squid with stage IV or $\mathrm{V}$ gonads in the total population. This appears to give a more satisfactory indication of cohort maturation for females than for males (Fig. 2). Male Illex mature faster than females (Rodhouse and Hatfield, 1990). This is supported by the maturation data from the fishery for the 1987-1991 fishing seasons with the sample data indicating $90-100 \%$ of males at stage IV or $\mathrm{V}$ after the first 3 or 4 months of the season. The female maturation data show wider variation in timing, with generally later maturation than males. The sigmoidal form of the logistic curve produces a reasonable description of the seasonal development in female maturity (Table $3 \mathrm{a}$ ). The male maturation data were less well fitted by a logistic curve (Table $3 \mathrm{~b}$ ), but the seasonal pattern in male maturation (stages IV +V; Fig. 2b) was relatively simple, with most variation in the first few months. The wide variation in the shape and fit of the maturation curves indicated that the model would need to be used to examine the effect of variation in the timing of maturation on cohort dynamics. For standard runs the maximum proportion reaching maturation was taken as $100 \%\left(\mathrm{P}_{\max }=1.0\right)$ for both male and female Illex. Standard maturation curves for male and female Illex utilized March and April as the respective months of $50 \%$ maturation.

Starting with the scaled 1987-1991 summed sample length-frequency data, under the standard fishing regime (Table 1 ), and natural mortality $(\mathrm{M})$ rate values of 2.9 and 0.5 (per annum), the model was used to simulate cohort development (Fig. 3). The more rapid maturation rate of male Illex $\left(\mathrm{k}_{\mathrm{m}}=\right.$ March; $\mathrm{k}_{\mathrm{f}}=$ April $)$ results in relatively few males present in the stock after the fourth month of the season. The slower growth rate of the males also results in a smaller mean size in any 
Table 3. (a) Statistics of the maximum likelihood fit of the logistic curve to the data on the proportion of female mature squid in the catch each month. (b) Statistics of the maximum likelihood fit of the logistic curve to the data on the proportion of male mature squid in the catch each month. The significance levels are: ns $=$ not significant, ${ }^{*}=p<0.05,{ }^{* *}=p<0.01,{ }^{* * *}=p<0.001$. Standard errors are given in brackets. Where no standard error is given then the model did not converge for the $\mathrm{P}_{\max }$ parameter.

(a)

\begin{tabular}{|c|c|c|c|c|c|c|}
\hline Year & Maturity data & Number of parameters fitted & $\mathrm{k}_{\mathrm{f}}$ & $P_{\max }$ & $r^{2}$ & Significance \\
\hline \multirow[t]{4}{*}{1987} & V & 2 & $4.2(0.11)$ & $0.44(0.09)$ & 84.0 & * \\
\hline & $I V+V$ & 2 & $4.1(0.91)$ & $0.82(0.23)$ & 70.8 & * \\
\hline & V & 1 & $6.1(0.34)$ & 1 & 43.3 & * \\
\hline & $I V+V$ & 1 & $4.6(0.36)$ & 1 & 75.4 & ** \\
\hline \multirow[t]{4}{*}{1988} & V & 2 & 6.7 & 0.87 & 79.8 & * \\
\hline & $I V+V$ & 2 & 4.6 & 1 & 97.2 & $* * *$ \\
\hline & V & 1 & $6.6(0.12)$ & 1 & 94.2 & $* * *$ \\
\hline & $I V+V$ & 1 & $4.6(0.10)$ & 1 & 97.9 & $* * *$ \\
\hline \multirow[t]{4}{*}{1989} & V & 2 & 2.6 & 0.65 & 37.4 & ns \\
\hline & $I V+V$ & 2 & 2.7 & 1 & 81.1 & $* *$ \\
\hline & V & 1 & $3.7(0.79)$ & 1 & 21.8 & * \\
\hline & $I V+V$ & 1 & $2.7(0.43)$ & 1 & 84.9 & $* * *$ \\
\hline \multirow[t]{4}{*}{1990} & V & 2 & $2.6(0.25)$ & $0.36(0.03)$ & 96.4 & $* * *$ \\
\hline & $I V+V$ & 2 & 2.9 & 1 & 92.1 & $* *$ \\
\hline & V & 1 & $5.3(0.35)$ & 1 & 15.3 & $*$ \\
\hline & $I V+V$ & 1 & $2.9(0.20)$ & 1 & 94.0 & $* * *$ \\
\hline \multirow[t]{4}{*}{1991} & V & 2 & - & - & - & ns \\
\hline & $I V+V$ & 2 & $1.7(0.84)$ & $0.47(0.06)$ & 24.3 & $* *$ \\
\hline & V & 1 & $6.8(0.53)$ & 1 & - & $\mathrm{ns}$ \\
\hline & $I V+V$ & 1 & $4.9(0.56)$ & 1 & - & * \\
\hline \multirow[t]{4}{*}{ All years } & V & 2 & $3.0(0.91)$ & $0.37(0.09)$ & 24.4 & $* * *$ \\
\hline & $I V+V$ & 2 & $3.2(0.47)$ & $0.80(0.10)$ & 57.2 & $* * *$ \\
\hline & V & 1 & $5.8(0.31)$ & 1 & 0.4 & ns \\
\hline & $I V+V$ & 1 & $3.8(0.24)$ & 1 & 53.8 & $* *$ \\
\hline
\end{tabular}

(b)

\begin{tabular}{|c|c|c|c|c|c|c|}
\hline Year & Maturity data & Number of parameters fitted & $\mathrm{k}_{\mathrm{r}}$ & $\mathrm{P}_{\max }$ & $r^{2}$ & Significance \\
\hline \multirow[t]{4}{*}{1987} & $\mathrm{~V}$ & 2 & $3.3(1.43)$ & $0.38(0.13)$ & 19.4 & ns \\
\hline & $I V+V$ & 2 & $0.7(0.49)$ & $1.00(0.02)$ & 55.5 & $* * *$ \\
\hline & V & 1 & $6.1(0.48)$ & 1 & - & ns \\
\hline & $I V+V$ & 1 & $0.8(0.26)$ & 1 & 69.7 & $* * *$ \\
\hline \multirow[t]{4}{*}{1988} & $\mathrm{~V}$ & 2 & $3.9(0.92)$ & $0.73(0.24)$ & 90.3 & * \\
\hline & $I V+V$ & 2 & 2.4 & 1 & 19.4 & $\mathrm{~ns}$ \\
\hline & V & 1 & $4.6(0.24)$ & 1 & 90.7 & ** \\
\hline & $I V+V$ & 1 & $2.4(1.00)$ & 1 & 46.3 & * \\
\hline \multirow[t]{4}{*}{1989} & V & 2 & $2.7(0.51)$ & $0.99(0.10)$ & 92.5 & * \\
\hline & $I V+V$ & 2 & 1.91 & 1 & 78.7 & * \\
\hline & V & 1 & $2.7(0.32)$ & 1 & 95.0 & $* *$ \\
\hline & $I V+V$ & 1 & $1.9(0.61)$ & 1 & 85.8 & ** \\
\hline \multirow[t]{4}{*}{1990} & V & 2 & $2.5(1.16)$ & $0.71(0.23)$ & 16.3 & ns \\
\hline & $I V+V$ & 2 & 0.4 & 1 & 92.1 & * \\
\hline & V & 1 & $3.7(0.47)$ & 1 & 31.5 & $* *$ \\
\hline & $\mathrm{IV}+\mathrm{V}$ & 1 & $0.4(0.16)$ & 1 & 92.6 & $* * *$ \\
\hline \multirow{4}{*}{1991} & V & 2 & - & - & - & $\mathrm{ns}$ \\
\hline & $I V+V$ & 2 & 1.0 & 1 & 94.8 & $* * *$ \\
\hline & V & 1 & $3.1(0.85)$ & 1 & - & $\mathrm{ns}$ \\
\hline & $I V+V$ & 1 & $1.0(0.10)$ & 1 & 96.5 & $* * *$ \\
\hline \multirow{4}{*}{ All years } & V & 2 & $2.4(0.71)$ & $0.62(0.10)$ & 29.8 & $* * *$ \\
\hline & $I V+V$ & 2 & 1.35 & 1 & 55.3 & $* * *$ \\
\hline & V & $\overline{1}$ & $4.2(0.32)$ & 1 & 13.8 & $* * *$ \\
\hline & $\mathrm{IV}+\mathrm{V}$ & 1 & $1.4(0.29)$ & 1 & 57.5 & $* * *$ \\
\hline
\end{tabular}



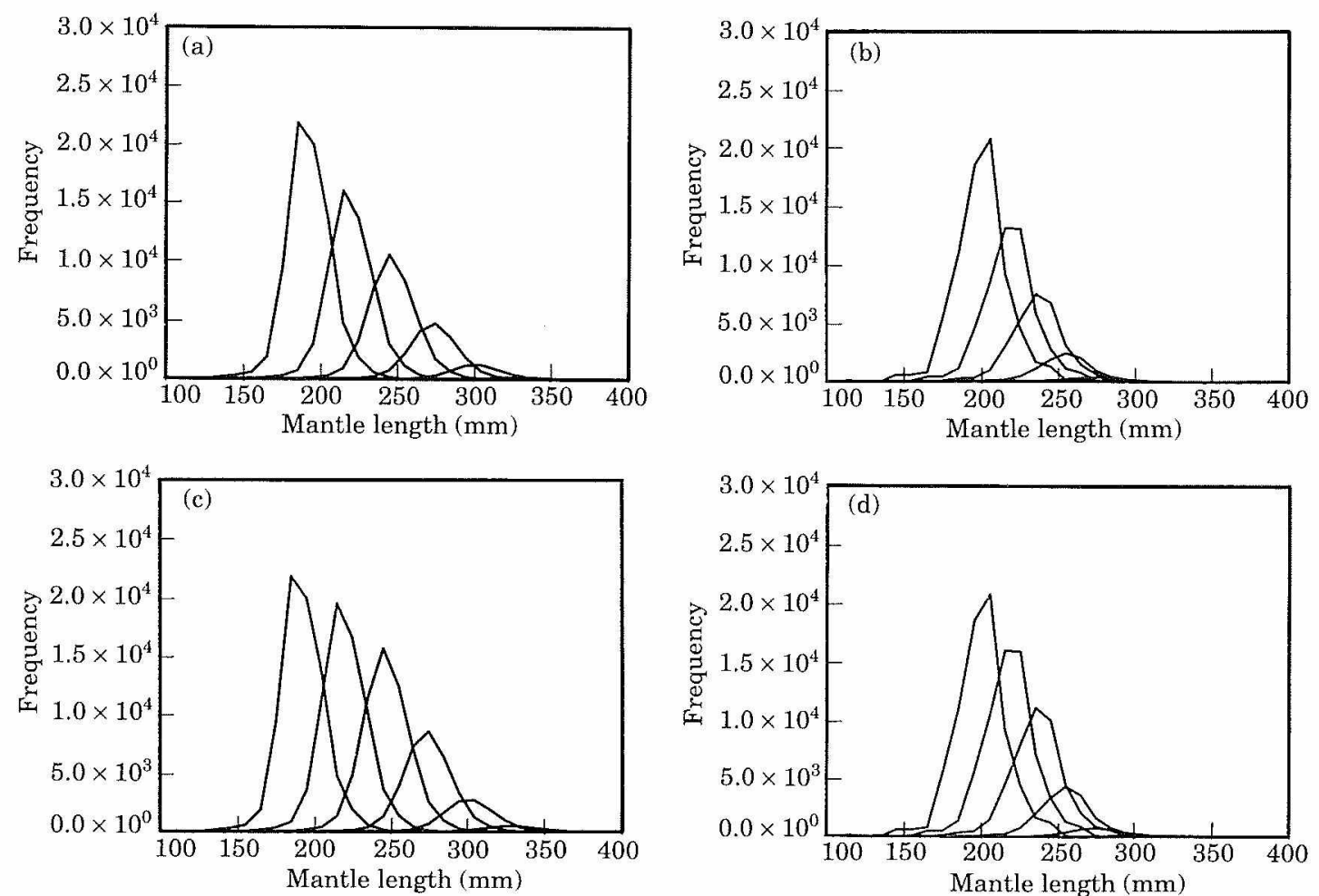

Figure 3. The development of a model Illex cohort through the season when fishing mortality is zero. The curves show the sizefrequency distributions in each month. (a) Female with $k_{f}=4$ and $M=2.9$. (b) Male with $k_{m}=3$ and $M=2.9$. (c) Female with $k_{f}=4$ and $\mathrm{M}=0.5$. (d) Male with $\mathrm{k}_{\mathrm{m}}=3$ and $\mathrm{M}=0.5$.

given month. Over a season in which the effort pattern results in $40 \%$ escapement [Equation (6)], a decline is observed in the male-to-female ratio in the catch. The effect of changing maturation rates of the two sexes on the sex ratio is shown in Figure 4. Variation in the relative rates of maturation can produce changes in the male-to-female ratio in the catch similar to that observed during the latter part of the season by Rodhouse $e t$ al. (1990). A combination of the timing of male maturation 1 month ahead of the females $\left[\mathrm{k}_{\mathrm{m}}=\right.$ March (3) and $\mathrm{k}_{\mathrm{f}}=$ April (4)] reproduces the general pattern of decline in sex ratio observed in the latter part of the season. In the early part of the season the model does not produce the changes observed. At the start of the season (FICZ) the ratio of males to females is close to unity. The maleto-female ratio then appears to increase over the first 2 to 3 months of the season, after that there is a decline. Immigration onto the ground probably continues during the first few months and the ratio changes indicate that the males immigrate more rapidly than females during this period. The decline in the ratio is probably due to a combination of the increased immigration of females and emigration of males.

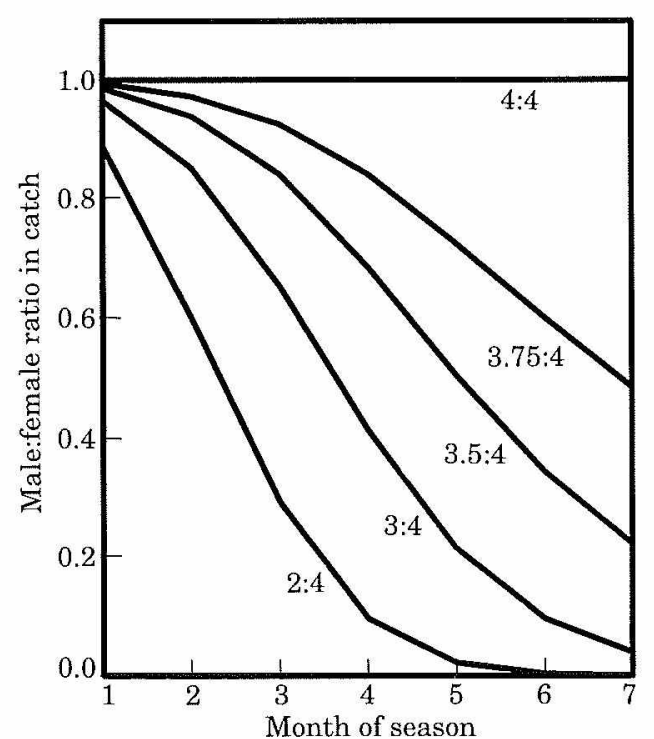

Figure 4. Curves showing the seasonal change in the ratio of male to female Illex in the catch for different combinations of the timing of male and female $50 \%$ maturation $\left(\mathrm{k}_{\mathrm{m}} \cdot \mathrm{k}_{\mathrm{f}}\right)$. A uniform fishing regime was applied. 


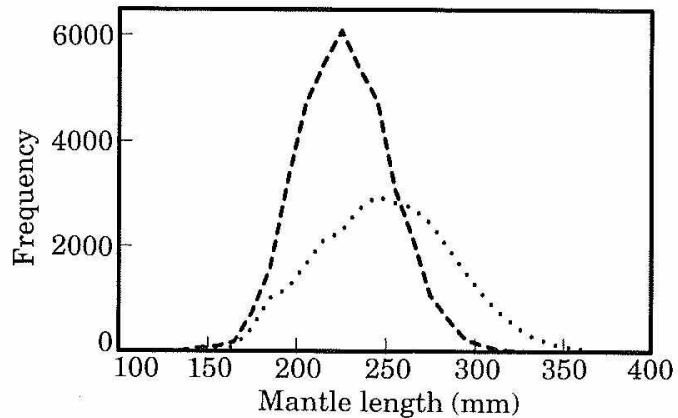

Figure 5. Model size-frequency distributions of mature Illex $\left(\mathrm{M}=2.9 ; \mathrm{k}_{\mathrm{m}}=3\right.$ and $\mathrm{k}_{\mathrm{f}}=4$ ); males (broken line) and females (dotted line). Based on $7.5 \times 10^{4}$ recruits of each sex at time zero. The standard fishing regime was applied.

The model can be used to examine the size-frequency distributions of the squid which successfully migrate from the ground over a whole season and form the spawning stock (Fig. 5). To do this it was assumed that on emigration there is no further mortality or growth. The effect of variation in the timing of $50 \%$ maturation on the mean mantle length of the male and female Illex in the reproducing stock (under the standard fishing regime, Table 1) is shown in Table 4a. The later the maturation the larger the mean size but the smaller the number of animals in the spawning stock. Particularly rapid increases in mean size are shown when the timing of $50 \%$ maturation is delayed from March to May. This increase in mean size is, however, associated with an increase in the variance (Table $4 \mathrm{a}$ ) and a reduction in numbers surviving to mature. In the early part of the season male and female squid are a similar size, but higher growth rates of female squid result in a greater increase in mean mantle size of mature animals with later maturation and longer growth periods. The relative number of squid surviving to spawn declines rapidly with later maturation (Table $4 a$ ). A reduction in the maximum proportion reaching maturity by the end of

Table 4. (a) Mean and standard deviation of mature Illex for different times of $50 \%$ maturation. $\mathrm{M}=2.9$ and $\mathrm{P}_{\max }=1.0$ for both sexes. (b) Length statistics of mature Illex with different parameter combinations. (a)

\begin{tabular}{|c|c|c|c|c|c|c|}
\hline \multirow[b]{2}{*}{ Month } & \multicolumn{3}{|c|}{ Male } & \multicolumn{3}{|c|}{ Female } \\
\hline & Mean length & Standard deviation & Number & Mean length & Standard deviation & Number \\
\hline January & 209.22 & 21.084 & 58542 & 206.57 & 23.588 & 58546 \\
\hline February & 217.03 & 23.568 & 50182 & 218.23 & 28.247 & 50182 \\
\hline March & 226.96 & 26.157 & 39592 & 233.03 & 32.825 & 39590 \\
\hline April & 238.35 & 28.876 & 28572 & 250.03 & 37.468 & 28573 \\
\hline May & 251.29 & 31.907 & 19255 & 269.33 & 42.455 & 19252 \\
\hline June & 265.23 & 34.238 & 12435 & 290.15 & 46.212 & 12433 \\
\hline July & 276.81 & 34.469 & 7393 & 307.42 & 46.542 & 7390 \\
\hline
\end{tabular}

(b)

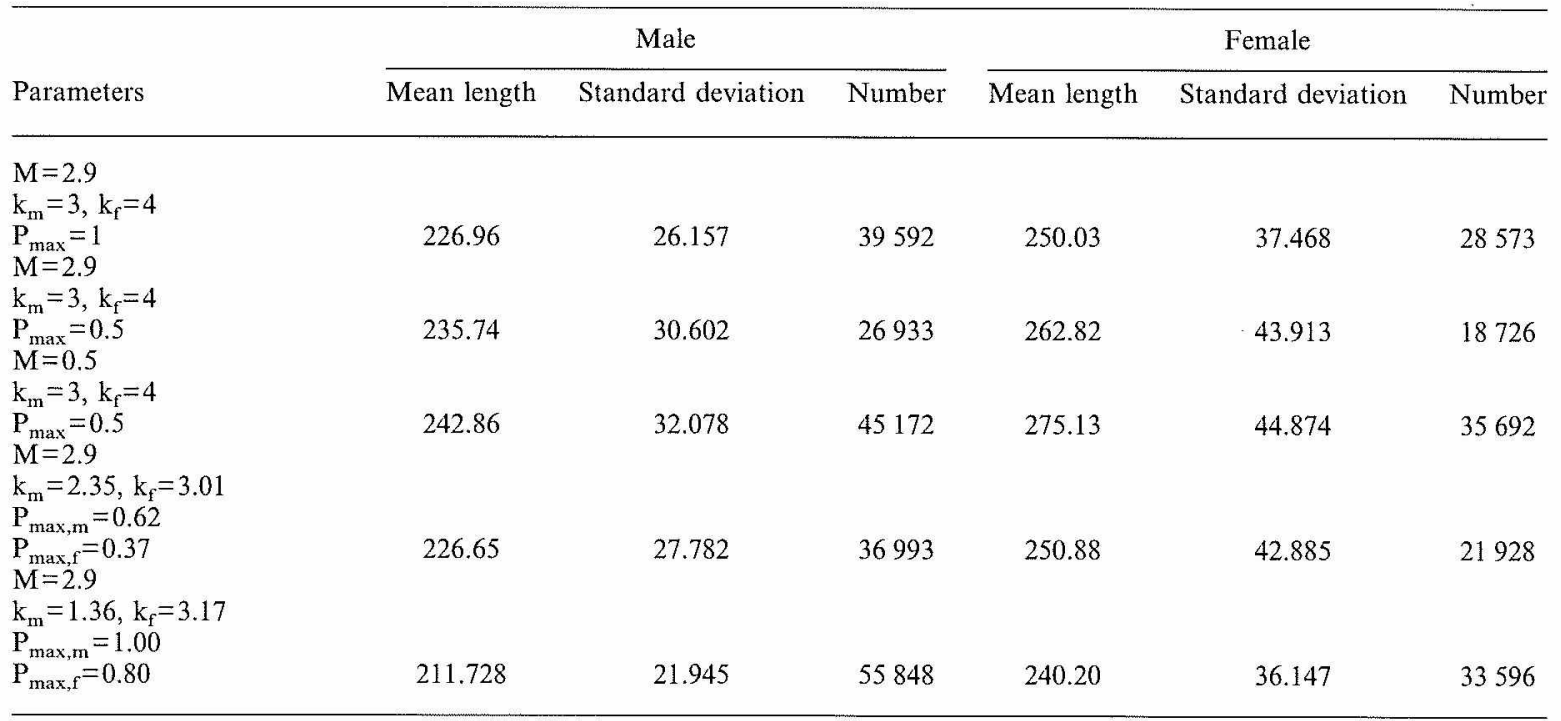




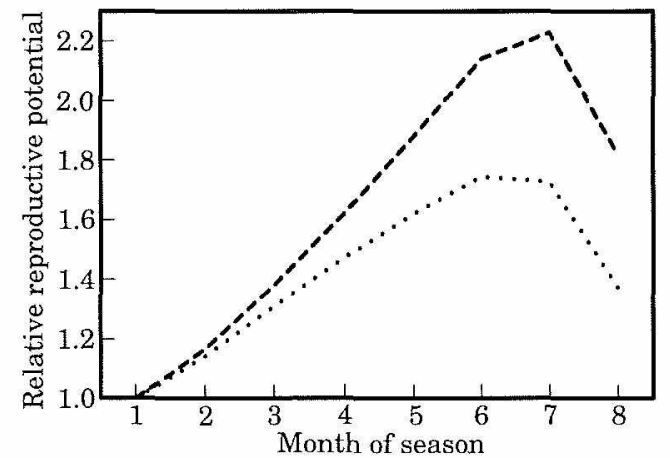

Figure 6. Changes in the relative reproductive potential of model Illex cohort with different months of $50 \%$ maturation. Values were normalized against the values for January (month 1). The female reproductive potential based on egg numbers is shown by the dotted line and the male reproductive potential based on the mass of the spermatophoric complex is shown by the broken line. The standard fishing regime was applied; $\mathrm{M}=2.9$.

the season has a similar effect to a later maturation (Table 4b). The mean length increases at the same time as the number surviving to maturity decreases. A reduced instantaneous rate of natural mortality cangenerate significant increases in the survival and mean size of the mature animals.

The larger female squid produce more eggs (Rodhouse and Hatfield, 1990) and the larger male squid have a larger spermatophoric complex, both of which are likely to result in increased reproductive potential.
By combining the empirical relationships described in Table 2 with the length-frequency data of mature animals we can investigate the effect of changing maturation rate on cohort reproductive potential. Such changes in maturation rate can produce a range of population egg productions and spermatophoric complex mass (Fig. 6). For both male and female squid the population reproductive potential increases with later maturation up to the sixth or seventh month and then decreases. These curves (Fig. 6) are the result of a tradeoff between the functions of growth increasing individual reproductive potential and increased mortality due to increased fishing mortalities with later maturation. The surface showing the within-season effects on egg production of changing the timing of $50 \%$ maturation (Fig. 7) indicates that for the parameter values used, the earlier the maturation then the earlier the month of peak production.

The catch curve when the $50 \%$ months of maturation are March and April for males and females, respectively, is shown in Figure 8a and has the same general shape of the catch curves obtained by Rodhouse et al. (1990). This indicates that the higher instantaneous rate of natural mortality was more appropriate as the lower rate would generate higher catch rates later in the season. However, some late season catches appear to be significant (Table 1) and suggest that late immigration or reduced mortalities may occur in some years. The size structure of the mature squid is shown in Figure 5, changes through the season in stock biomass are given in Figure $8 \mathrm{~b}$. The size structure is the combined structure

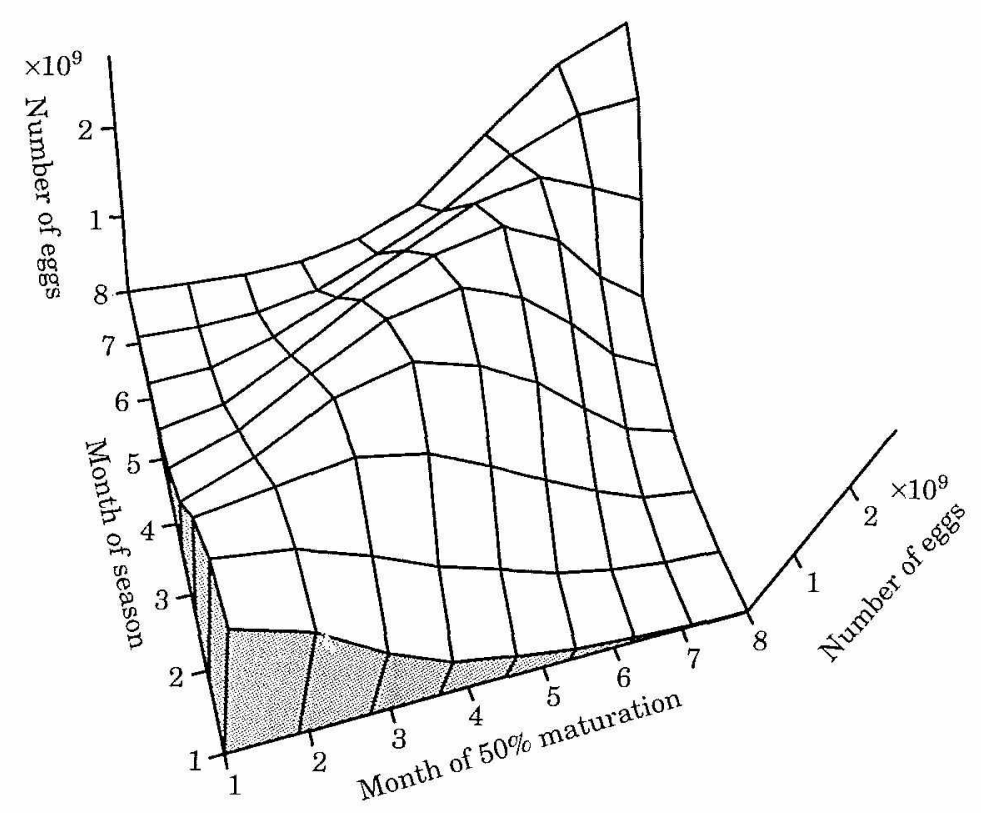

Figure 7. Surface showing the numbers of eggs produced each month by the model cohort $\left(7.5 \times 10^{4}\right.$ squid) with different months of $50 \%$ maturation $(M=2.9)$. Standard fishing regime applied. 

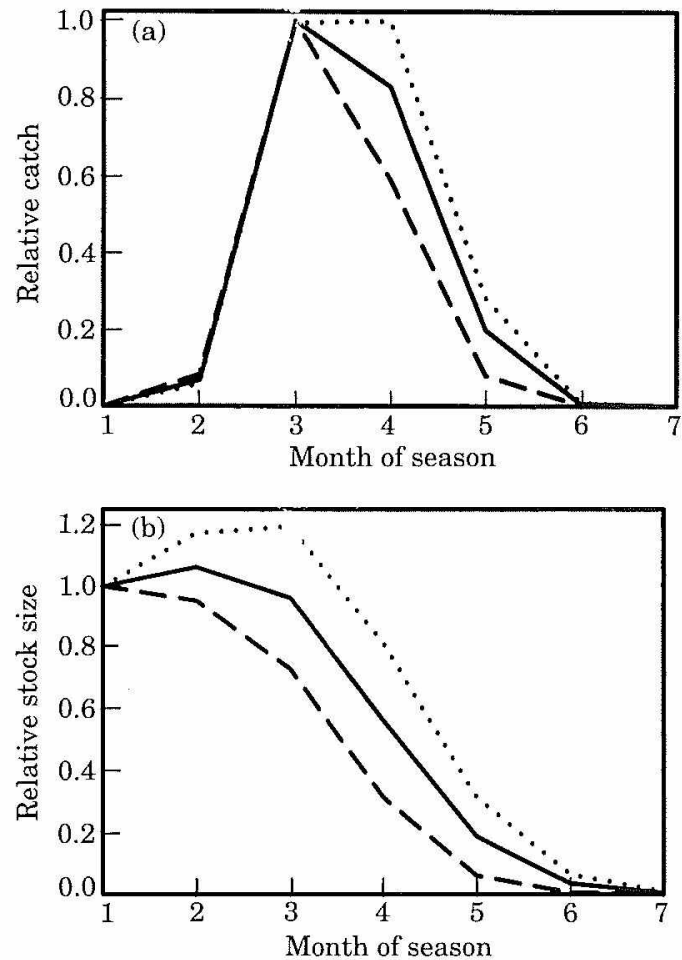

Figure 8. (a) The seasonal change in the relative catch (mass) of Illex. Catches were normalized against the maximum values. (b) Relative change in stock biomass through the season $(\mathrm{M}=2.9$; $\mathrm{k}_{\mathrm{m}}=3$ and $\mathrm{k}_{\mathrm{f}}=4$ in both cases). Biomasses were normalized against the values for January. Standard fishing regime applied. Solid line is for the total population, the dotted line is for females, and the broken line for males.

for all squid that matured and migrated off the feeding ground during the whole season. The mature males have a smaller mean size and the coefficient of variation is also smaller; $11.5 \%$ versus $15.0 \%$. Two aspects of the fishery were investigated using the model, the effect of the escapement policy on spawning stock size and of changing the pattern of fishing on the yield. The effect of the escapement policy on the stock size [Equation (4), $X=0.4]$ and on the spawning stock size are shown in Figure 9. Later maturation results in reduced escapement for the spawning stock. Delaying maturation in this model has the same effect as adding a time lag to the emigration following maturation; thus, a delay after maturation before leaving the ground will reduce escapement. The stock escapement curve (Fig. 9) shows a very similar pattern to that obtained by Beddington et al. (1990), even though the stock on the ground is reduced to near-zero levels late in the season because of the emigration (Fig. 8b).

If the effort is restricted to a single month with the same final escapement achieved for the stock [Equation (6), $X=0.4]$, then after the first 3 to 4 months there is a decline in total catch (Fig. 10a). For the later-maturing

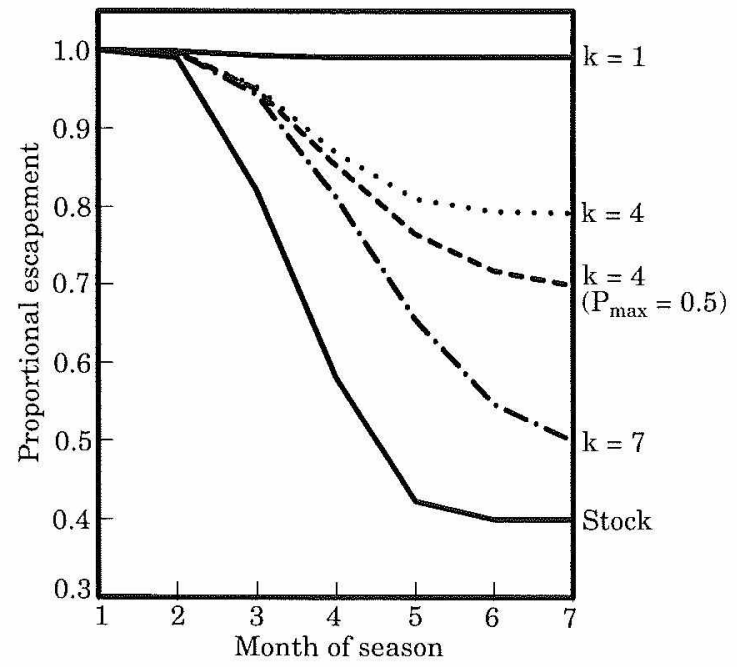

Figure 9. The seasonal change in proportional escapement of Illex from the fishable stock and the mature reproducing stock with different times $(\mathrm{k})$ of $50 \%$ maturation $(\mathrm{M}=2.9)$. Standard fishing regime applied. The maximum proportion reaching maturity $\left(\mathrm{P}_{\max }\right)$ is 1 unless stated otherwise.

females higher catches are maintained by later season fishing than for males. The model overestimates the availability of the squid in the early part of the season, when they are probably still immigrating. Later exploitation results in an increase in the relative reproductive potential of the spawning stock reflecting the increased maturation of the stock through the season, but the model results are not sensitive to this effect (Fig. 10b). However, due to the emigration of mature organisms later maturation results in a large increase in the total catch (Fig. 10c), with the largest increases occurring with maturation delayed until about April/May.

\section{Discussion}

\section{Illex argentinus migration}

The life history and migration patterns of Illex argentinus are gradually being elucidated, but there remain a number of areas of uncertainty. In the model developed above we have assumed that the migration pattern is associated with maturation. Arkhipkin (1993) has recently analysed data from fisheries operating late in the season in three regions; to the west of the Falkland Islands at $52^{\circ} \mathrm{S}$, and north along the shelf break at $46^{\circ} \mathrm{S}$ and $42^{\circ} \mathrm{S}$. These analyses suggest that there is a wave of migration from south to north between April and June. In each region the ratio of males to females in the catches decreases through the fishing season. The effect of the maturation-dependent migration pattern, upon which the model is based, is that the male-to-female ratio of the mature stock leaving the ground should be greater than 1 early in the season and should decline as 

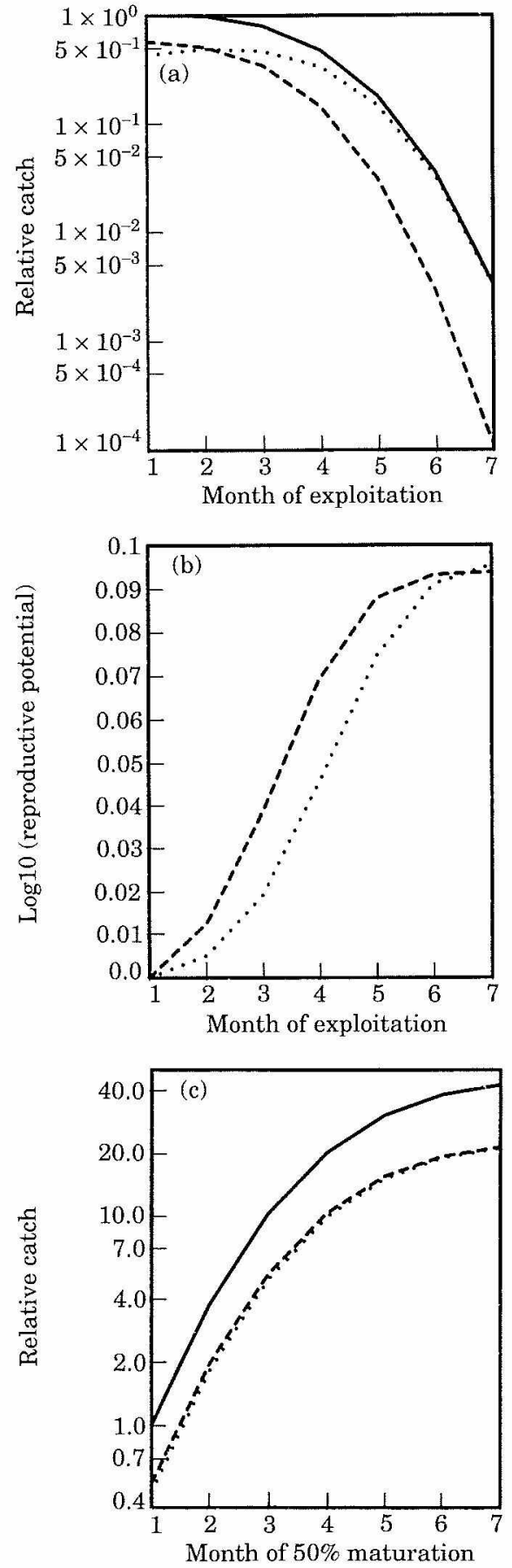

Figure 10. (a) The relative change in total catch from the fishery over the whole season with different months of exploitation $(M=2.9)$. Values were normalized by the maximum total catch. (b) Cohort-relative reproductive potential against month of exploitation. Values were normalized against the values for January. (c) Change in the total catch from the fishery for different months of $50 \%$ maturation with the standard fishing regime. Values were normalized against the total catch in January. All relative scales are logarithmic. Other definitions as in Figure 8. the season continues. The consistent picture that emerges from the data analyses and model is that the males are maturing and leaving the feeding grounds in the south earlier than the females. There does not have to be a large difference in the maturation timing between the males and females to see the change in sex ratio in the temporal sequence of the catches. The results indicate that the wave of male maturation-migration is about 1 month ahead of the female wave. By the time the fishery opens and reasonable catch rates are obtained the value of the male-to-female ratio in the catch is about 1 . Over the next couple of months the male-to-female catch ratio declines. The mature squid head north in a large wave, which may be split into smaller waves (Arkhipkin, 1993). This wave of biomass takes a couple of months to pass an area. In any area that this large wave passes the ratios are greater than or close to unity at the start of fishing, and much less than one towards the end. We would expect that samples taken in these areas prior to the start of the main fishing season would show catches dominated by males.

There does not appear to be a development of percentage maturity in the population from the Arkhipkin (1993) data, and this is generally consistent with the model in that only animals close to maturity would be migrating. In areas $46^{\circ} \mathrm{S}$ and $42^{\circ} \mathrm{S}$ this appears to be the case, but, in the $52^{\circ} \mathrm{S}$ area, the proportion mature stays low during the catch period. This may indicate a poorer feeding area or a lack of connection with the major wave of migration, although Arkhipkin (1993) does state that the great majority of the females were maturing. The implication of this view is that management policy will need to take account of the connections within the fishery as the spawning stock biomass is dependent on the combined effects of fishing in these regions.

Cannibalism, as observed in Illex illecebrosus (O'Dor, 1983), may also be important in the generation of the sex ratios, and, given the relative sizes of the males and females, may tend to emphasize further the changes in sex ratio observed. However, although cannibalism may have been an important factor in the evolution of the differential migration of the males and females, the model shows that it is not a necessary requirement to generate the changes in sex ratio observed.

\section{Within-season fishing effects}

The model reproduces well the general pattern of cohort decline and cumulative catch observed in the fishery. The change in catch per unit effort (CPUE) in the early part of the season (Rodhouse et al., 1990) indicates a change in the catchability coefficient or continuing recruitment into the fishery. The interannual variation in the shape of the curves describing the seasonal changes in the maturity curves and the ratio of male to female squid in the catch (Rodhouse et al., 1990) suggests that 
there is large variation from year to year in the timing of the maturation within and between the two sexes. The fluctuations in the ratio in the early part of the season indicate that there are differences in recruitment or catchability of the two sexes. These were not included in the model, but the model does reproduce the variation in ratios observed in the latter part of the season simply by changes in relative maturation rates. The model could be extended to include immigration changes if data were available.

The model results show that variation in the timing of maturation in this fishery can affect the mean size of squid in the spawning stock. Early maturation of squid results in the mean size of the migrating squid, which become the spawners, being reduced, and these have a reduced reproductive potential (i.e. fewer eggs). Later maturation at a larger size increases the individual reproductive potential (large numbers of eggs). However, the probability of surviving the prolonged exposure to the fishery decreases for later-maturing squid. The success of the contribution of an individual's genes to the next generation is, therefore, likely to be dependent on a tradeoff between the survival and the fecundity functions and for individual squid the age of maturation can be considered as the optimization of these two functions (Roff, 1992).

The optimum strategy for an individual squid to maximize fitness in this system, based on the survival and fecundity functions, may not be the same as that for the maintenance of the population. This will depend on a number of factors, such as egg survival, which may be affected by the timing of spawning and size-dependent predation in which natural mortality rates may be greater for smaller individuals. The peak population reproductive potential in the standard run of the model was produced by a relatively few latematuring squid. The data available show that the month of $50 \%$ maturation in the Illex population occurs before the maximum cohort reproductive potential is reached. Thus, the population is generating a reproductive effort well below the maximum possible. Greater mortalities during the latter part of the season, due, for example, to increased fishing mortalities, would further tend to reduce the reproductive potential of the population.

The model analyses did not address what happens to the migrating population once it leaves the ground. It was assumed that these processes would only produce a scaling in the absolute reproductive potential and not in the relative potential between different maturation scenarios. A delay could be introduced into the model to allow for migration from the fishing ground, during which time further mortalities and growth could occur (Arkhipkin, 1993); however, more detailed analysis of the migration and the spawning population would be useful. One effect that may be important is any levelling off of the growth rate. In the model this was taken to be linear during the fishing season. This type of organism does not necessarily show asymptotic growth (Alford and Jackson, 1993); however, any non-linear changes late in the season could effect the relative changes in reproductive potential.

It is clear that the fishery can be profoundly affected by the factors considered in the model. The effect of the maturation and emigration of squid during the fishing season is likely to produce higher levels of escapement for the spawning stock than that indicated by utilizing the fishery data which applies to the stock on the fishing ground. The current management policy is likely to be conservative in terms of maintaining a spawning stock of sufficient size (Rosenberg et al., 1990). The later the maturation and emigration of the squid cohort the more representative the fishery data will be of the escapement for the spawning stock.

Under the current fishing regime, with $50 \%$ maturation of males during March and during April for females, the model shows that the concentration of effort in the third to fourth months of the season will generally produce greatest yields from the fishery. During the first 2 months of the season the characteristics of the fishery appear to be different, resulting in low catch rates. In general, later maturation results in higher catches being obtained. For a given maturation time early to midseason harvesting gives the greatest yield from the fishery, but this results in reduced reproductive potential in the spawning stock.

\section{Long-term implications}

The above discussion has only been concerned with the cohort dynamics within a season. In reality the size of the recruiting year class in this species is likely to be greatly affected by environmental variations. For the population, the overall reproductive potential will depend on the overall stock level at the start of the season, and, hence, the number that survive to spawn. The implication from the above analyses is that in years when maturation is early the reproductive potential will be reduced. Thus, any stock recruit relationship (Beddington et al., 1990) may include an aspect of timing of maturation in the previous season. The model demonstrates that there is a wide variation in the probability of spawning for individual squid which mature at different sizes. In this annual species there is thus a great potential for the selective action of the fishery to influence the life-history strategies of the squid. The fishery will tend to select for maturation at smaller size if the characteristics show any degree of heritability. Other factors may favour the few large animals which mature and spawn, and there may also be other selective factors later in the life cycle (e.g. egg size) which modify the relative fitness of larger organisms. 
The important question which the model poses is to what extent are the characteristics determining the timing of maturation inherited? Roff (1992) suggests that, although life-history traits show lower heritabilities than behavioural or physiological traits, the heritabilities are likely to be significant.

There is a range of evidence from studies of various fish species and other aquatic organisms (Nelson and Soule, 1987; Edley and Law, 1988) that such selective effects of fishing can be observed in later generations. Earlier maturation has been recorded in size-selective fisheries (Ricker, 1981; Law and Grey, 1989). Although the action of the jigging gear in the Illex fishery is likely to be less size selective than that of nets, the effect of variation in the maturation rate and subsequent emigration provides a mechanism by which size selectivity can occur. It seems likely that in a semelparous species in which there is no intermixing of genetic material between cohorts that selective effects will be emphasized.

As we have seen above, any selection for small maturation size is likely to result in reduced reproductive potential for the population, and, as demonstrated, this can lead to a reduced yield from the fishery. However, the model indicates that peak yield is obtained by fishing effort patterns concentrating on the mid-part of the season, relatively early in terms of maturation. Yield may therefore remain high even though reproductive potential is decreasing. This may increase the potential for undetected trends in stock recruitment. Such effects are also likely to be masked in a species in which large-scale environmental factors, such as inter-annual variability in the Falkland Current, have an important role in recruitment (Rodhouse et al., 1992). The changes in mean mantle size of organisms in the catch may give a poor indication of the size of the organisms which survive to spawn, so this could also make the detection of a trend of changing size in the fishery more difficult.

The data available to this study are insufficient and not of long enough duration for detecting any trends in this fishery. The maturity stage data from the fishery are equivocal, so there is a need for further study of the maturation of Illex in this area. A more objective determination of the maturation of Illex specimens is required to monitor possible changes in the reproductive potential of the stock. Recording of gonad weight or energy content would be useful.

There is undoubtedly heterogeneity in the distribution of squid as they are known to show schooling behaviour (O'Dor, 1983). Such behaviour may be associated with a non-random distribution of organisms between schools in terms of individual size or maturity stage, as has been observed for krill (Euphausia superba) (Watkins et al., 1986, 1990). An analysis of the schooling characteristics of this species would appear to be a fundamental requirement. Such behaviour may introduce serious bias into population samples if they are taken from a rela- tively small proportion of the population of different schools. To improve knowledge of the population dynamics of Illex a thorough analysis of operation of the fishery and stock distribution are needed, along with an investigation of the emigration on reaching maturity. The conclusion from the above model is that emigration immediately following maturation is likely to be important. Mating does not appear to occur on the fishing ground. Emigration from the ground may not occur immediately following maturation, but reduced feeding and hence vulnerability to the fishery would have the same effect. A wide range of hatching times over a 4-5month period was indicated by analyses of statolith samples (Rodhouse and Hatfield, 1990; also Arkhipkin, 1991). This indicates that emigration from the ground to the spawning area with variable timing in spawning occurs. Further information is needed on this aspect.

With such an emigration effect a size-selective cropping is possible. Evolution of the yield from the fishery may be occurring (Law and Grey, 1989). If the heritabilities of key life-history traits, such as size of maturation, are significant then selective changes may be occurring in this fishery. The short generation time and semelparous nature of this species would emphasise these effects. We have seen that the yield, size of the spawning stock, and the size of reproductive organisms can be affected by the fishery. The conservative nature of the management policy does not rule out that evolution may occur in this stock. The potential effect is that evolution of the population towards a reduced reproductive potential could result in stock collapse. The investigation of the concept of an evolutionary stable optimal harvesting strategy (Law and Grey, 1989) may be fundamental for such a short-lived species. Genetic studies of this species have already commenced (Carvalho et al., 1992). Future modelling work should test the sensitivity of the system to different heritabilities of the key life-history characteristics and investigate the selective potential of the fishery over a number of generations.

\section{Acknowledgements}

We thank Dr G. Tingley and Dr L. Coelho for various discussions on aspects of Illex population dynamics. Research at the British Antarctic Survey on aspects of the life cycle of Illex argentinus is funded by the Falkland Islands Government.

\section{References}

Alford, R. A., and Jackson, G. D. 1993. Do cephalopods and larvae of other taxa grow asymptotically? The American Naturalist, 141: 717-728.

Arkhipkin, A. 1990. Edad y crecimiento del calamar Illex argentimus. Frenie Maritimo, 6 (Sec. A): 25-35. 
Arkhipkin, A. 1993. Age, growth, stock-structure and migratory rate of pre-spawning short-finned squid Illex argentinus bas on statolith ageing investigations. Fisheries Research, 16: 313-338.

Beddington, J. R., Rosenberg, A. A., Crombie, J. A., and Kirkwood, G. P. 1990. Stock assessment and the provision of management advice for the short fin squid fishery in Falkland Islands waters. Fisheries Research, 8: 351-365.

Caddy, J. F. 1979. Preliminary analysis of mortality, immigration and emigration of Illex populations on the Scotian Shelf. ICNAF Research Document. 79/VI/120. 21pp.

Caddy, J. F. 1990. Modelling natural mortality with age in short lived invertebrate populations. Shellfish life histories and shellfishery models, ICES Symposium, Moncton, New Brunswick, Canada, June 1990.

Carvalho, G. R., Thompson, A., and Stoner, A. L. 1992. Genetic diversity and population differentiation of the shortfin squid Illex argentimus in the south-west Atlantic. Journal of Experimental Marine Biology and Ecology, 158: 105-121.

Csirke, J. 1987. The Patagonian fishery resources and the offshore fisheries in the southwest Atlantic. FAO Fisheries Technical Paper 286: 75pp.

Edley, M. T., and Law, R. 1988. Evolution of life histories and yields in experimental populations of Daphria magna. Biological Journal of the Linnaean Society, 34: 309-326.

Hurley, G. V., and Mohn, R. K. 1979. Considerations on the management of the international squid (Illex) fishery in ICNAF subarea 4. Technical Report of the Fish Marine Service of Canada 79/VI/11 Ser. No. 5419.

Law, R., and Grey, D. R. 1989. Evolution of yields from populations with age-specific cropping. Evolutionary Ecology, 3: 343-359.

Lipinski, M. 1979. Universal maturity scale for the commercially important squids. The result of maturity classification of the Illex illecebrosus population for the years 1973-77. ICNAP Research Document 79/2/38, Serial 5364: 40pp.

Nelson, K., and Soulé, M. 1987. Genetical conservation of exploited fishes. $I n$ Population genetics and fisheries management, pp. 345-368. Ed. by N. Ryman and F. Utter. University of Washington Press, Seattle and London.
O’Dor, R. K. 1983. Illex illecebrosus. In Cephalopod life cycles: species accounts. Vol. I, pp. 175-199. Ed. by P. R. Boyle. Academic Press, London.

Payne, R. W., Lane, P. W., Ainsley, A. E., Bicknell, K. E., Digby, P. G. N., Harding, S. A., Leech, P. K., Simpson, H. R., Todd, A. D., Verrier, P. J., and White, R. P. 1987. GENSTAT 5 reference manual, Oxford University Press, Oxford.

Ricker, W. E. 1981. Changes in the average size and average age of Pacific salmon. Canadian Journal of Fisheries and Aquatic Science, 38: 1636-1656.

Roff, D. A. 1992. The evolution of life histories; theory and analysis. Chapman \& Hall, London. 535 pp.

Rosenberg, A. A., Kirkwood, G. P., Crombie, J. A., and Beddington, J. R. 1990. The assessment of stocks of annual squid species. Fisheries Research, 8: 335-350.

Rodhouse, P. G., and Hatfield, E. M. C. 1990. Dynamics and maturation in the cephalopod Illex argentinus de Castellanos, 1960 (Teuthoidea: Ommastrephidae). Philosophical Transactions of the Royal Society, London, B, 329: 229-241.

Rodhouse, P. G., Barton, J., Hatfield, E. M. C., and Symon, C. 1990. Illex argentinus (Cephalopoda: Ommastrephidae): life cycle, population structure and fishery. ICES 1990 Shellfish Symposium, no. $1.26 \mathrm{p}$.

Rodhouse, P. G., Symon, C., and Hatfield, E. M. C. 1992. Early life cycle of cephalopods in relation to the major oceanographic features of the southwest Atlantic Ocean. Marine Ecology Progress Series, 89: 183-195.

Sissenwine, M. P., and Tibbetts, A. M. 1976. Simulating the effect of fishing on squid (Loloigo and Illex) populations of the Northeastern United States. ICNAF Selected Papers, no. 2: 71-84.

Watkins, J. L., Morris, D. J., Ricketts, C., and Priddle, J. 1986. Differences between swarms of Antarctic krill and some implications for sampling krill populations. Marine Biology, 93: 137-146.

Watkins, J. L., Morris, D. J., Ricketts, C., and Murray, A. W. A. 1990. Sampling biological characteristics of krill: effect of heterogeneous nature of swarms. Marine Biology, 107: $409-415$. 